\title{
Pressupostos éticos da educação da solidão
}

\author{
Professor Titular da Pontifícia Universidade Católica de Campinas \\ Doutor em Educação pela UNICAMP
}

\section{Resumo}

Este artigo discute os pressupostos éticos da educação da solidão, compreendida como educação aristocrática ou educação do solitário. Abordase alguns pressupostos da ética aristocrática em Heráclito, a partir de diversos comentadores, com o intento de evidenciar que a noção de ética aristocrática encontra amparo na vivência do filósofo obscuro, além de tratar da questão do $\lambda o ́ \gamma o \varsigma$, no sentido de explicitar que a vida aristocrática não diz respeito a qualquer vida, mas à vida desperta. Em seguida, aborda-se a educação aristocrática como educação da solidão e, neste contexto, busca-se responder à questão central do artigo que consiste na pergunta: quais os pressupostos éticos da educação da solidão? $\mathrm{O}$ método consiste em revisão bibliográfica, dado se tratar de investigação realizada no contexto de fundamentos da educação, mais precisamente de filosofia da educação. Os resultados alcançados apontam para três pressupostos éticos da educação da solidão com destaque para a excelência individual.

Palavras-chave: Ética; Singularidade; Educação da Solidão.

\begin{abstract}
This article discusses the ethical education of solitude, understood as aristocratic education or education of solitarian. It approaches some assumptions of aristocratic ethics in Heraclitus, from several commentators, with the intent of showing that the notion of aristocratic ethics finds support in living the obscure philosopher, and address the issue of dó ${ }^{\circ}$, in the sense to clarify that the aristocratic life is not about any life but its waking life. Then, it approaches the aristocratic education as education of solitude and in this context, we seek to answer the central question of the article: what the ethical education of solitude? The method is based on literature review dealing with research conducted in the context of foundations of education, specifically in the philosophy of education. The results point to three ethical premises of the solitude of education with emphasis on individual excellence.
\end{abstract}

Key-words: Ethics; Singularity; Education of Solitude. 


\section{Introdução}

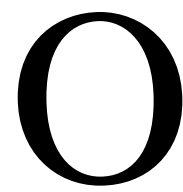

artigo intitulado Pressupostos éticos da educação da solidão é o resultado da apresentação do texto Reivindicação ética e singularidade, no I Simpósio Nacional sobre Política, Ética e Educação, Poiethos, na Universidade Estadual de Campinas. Este texto tem estreita relação com a tese defendida em 2009, na mesma Universidade, que tratou da educação aristocrática em Nietzsche. Com efeito, não se trata de desenvolver a tese da educação aristocrática para tratar da reivindicação ética e singularidade, todavia, será absolutamente fundamental tratar desta concepção de educação, que pode ser compreendida como educação da solidão.

A educação da solidão, sinônimo do que entendemos por educação aristocrática, não diz respeito a um modelo de educação a ser implantado no sistema educacional, todavia, refere-se à crítica da educação de massas e, portanto, a possibilidade de releitura e de recolocação da educação no seu lugar de destaque, isto é, aponta para a necessidade da educação a ser pensada a partir de pressupostos éticos. Ética fundada na vida individual e solitária de Heráclito e Nietzsche, por um lado, na contínua reivindicação da autossuperação e autocrítica e, por outro, educação considerada como lugar da tomada de consciência do sujeito, dizem respeito às matrizes teóricas deste artigo. Pretende-se discutir aspectos de uma concepção ética que insere a autossuperação como pressuposto do sujeito que reivindica uma educação singular que nomeamos aristocrática. O filósofo da vontade de potência reivindica o aparecimento do espírito muito livre ou filósofo do futuro como articulador e protagonista de sua autocrítica na sociedade.

Assim, do ponto de vista formal, discute-se alguns pressupostos da ética aristocrática em Heráclito, a partir de diversos comentadores, com o intento de evidenciar que a noção de ética aristocrática encontra amparo na vivência do filósofo obscuro. Discute-se, também, elementos da ética aristocrática em Heráclito, em específico a questão do $\lambda o ́ \gamma o \varsigma$, no sentido de evidenciar que a vida aristocrática não diz respeito a qualquer vida, mas à 
vida desperta. Em seguida, aborda-se a educação aristocrática como educação da solidão e, neste contexto, busca-se responder à questão central do artigo que consiste na pergunta: quais os pressupostos éticos da educação da solidão?

\section{Ética aristocrática em Heráclito}

Heráclito propõe como objeto da busca da verdade do filósofo, a ética aristocrática. Não é por acaso que ele não teve mestre, pois o conhecimento não requer o outro exterior a si mesmo, necessariamente, mas pode partir da própria consciência, em se tratando da ética aristocrática. E não é casual também que Heráclito propunha o recolher-se em si mesmo como uma maneira de livrar-se da ignorância.

A ética aristocrática em Heráclito (Mendonça, 2003) é objeto de reflexão de diversos pensadores. Sua relação com a educação da solidão ou educação aristocrática é estreita, na medida em que a educação da solidão aponta para a busca do sujeito, da mesma forma que a ética aristocrática diz respeito à dimensão individual da própria ética. De um modo geral, diz respeito a uma ética em que o filósofo busca se superar continuamente na busca de si mesmo, sem se preocupar com a vida pública. O que importa é a tomada de consciência do seu papel individual no mundo. Justifica-se deste modo o recolher-se do filósofo, tanto na vivência com o outro, quanto na vivência consigo mesmo. Não é papel da ética heracliteana preocupar-se com o vulgo. Por esta razão o tratamento ao povo, por Heráclito, é com desdém, como ressalta Kirk (1966, p. 216):

Heráclito era, sem sombra de dúvida, de um temperamento acentuadamente crítico, e a sua linguagem insultuosa dificilmente o pode ter tornado popular aos olhos dos seus mal afortunados concidadãos. As suas idéias políticas parecem ter sido antidemocráticas, embora, talvez, por razões mais empíricas do que ideológicas: 'Para mim, um homem vale mais por dez mil, se for o melhor', disse ele, e censurou asperamente os Efésios por exilarem o seu amigo Hermodoro sob o pretexto das suas excepcionais aptidões. Sendo ele próprio de nobre nascimento, recusou os privilégios tradicionais que lhe cabiam. 
Para Kirk, a ética aristocrática é enfatizada por Heráclito, que aproxima pela primeira vez, a ética da física. O fragmento "Procurei-me a mim mesmo", fundamenta-se de maneira implícita na teoria física de Heráclito. Diz Kirk (1966, p. 216):

Os conselhos éticos de Heráclito são gnômicos na forma, e na maior parte semelhantes, quanto ao conteúdo geral, aos dos seus predecessores e contemporâneos; por vezes são expressos de uma maneira mais pictórica e frequentemente mais crua. Sublinham a importância da moderação, que depende, também ela, de uma apreciação correta das faculdades de cada um. Mas esta espécie de conselhos (a que naturalmente se comparam as máximas délficas 'Conhece-te a ti mesmo' e 'Nada em excesso') tem um significado mais profundo em Heráclito, porque se fundamenta nas suas teorias físicas, e é devida à sua crença de que só pela compreensão do modelo central das coisas pode um homem tornar-se sábio e completamente eficiente. É esta a verdadeira moral da filosofia de Heráclito, em que a ética é pela primeira vez formalmente entretecida com a física.

Então, Kirk conclui que o comportamento humano, tanto quanto as

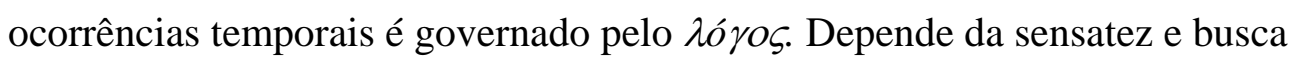

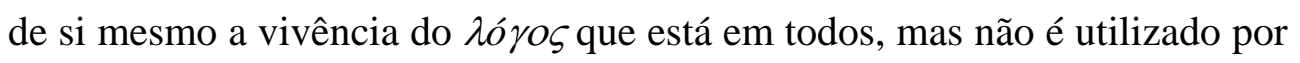
todos. Em outras palavras, a ética heracliteana sustenta a busca da superação da vida, no sentido de ressignificar os valores instituídos como busca do $\lambda o ́ \gamma o s$. É preciso viver a vida desperta para que a vida tenha sentido, então, a ética aristocrática, neste sentido, sinaliza para o fortalecimento da individualidade frente aos desafios do cotidiano.

Em Baker, a apologia a uma ética aristocrática feita por Heráclito é ainda mais evidente, pois o filósofo obscuro considera que a guerra está na origem de todas as coisas e é dever do homem unir-se ao fogo. Ele representa o $\lambda o ́ \gamma o \varsigma$, a lei que governa todas as coisas e vitaliza o homem na vida. Todas as leis humanas são sustentadas pela lei divina, que é forte e suficiente. Diz Baker (1995, p. 57):

(...) as leis humanas são explicadas pela lei física, esta dá vida às leis do mundo moral. As leis são emanações daquela Lei fundamental; são encarnações da substância comum do mundo e da alma, que é o fogo. Este tipo de raciocínio levou Heráclito a uma posição aristocrática: 'Embora a sabedoria seja comum a 
toda a sociedade, o povo vive como se tivesse uma sabedoria própria'.

Que tipo de sabedoria tem o povo? Constata-se ações humanas boas e más. Em conjunto o homem tende a fazer o mal e isoladamente tende a fazer o bem. Por esta razão, diz Baker, citando Heráclito: "Os efésios deveriam ser enforcados: expulsaram Hermodoro, o melhor deles todos, por não admitirem um cidadão que fosse melhor que os outros". (Baker, 1995, p. 58)

A conclusão de Baker não é diferente da de Kirk, em se tratando da ética aristocrática de Heráclito, pois este percebeu a natureza como uma

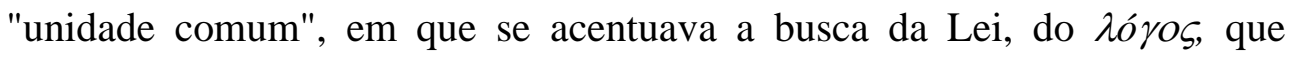
governa tudo. A fundamentação da ética de Heráclito então se coloca na

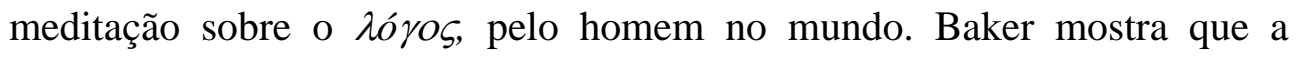

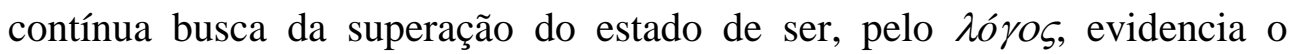
caráter aristocrático da ética em Heráclito.

Solange Vergnières (1998, p. 16) apresenta um minucioso estudo acerca da natureza do ethos. Para isto, analisa o ethos aristocrático antes de Aristóteles, mostrando que o que garante a excelência aristocrática é justamente a formação educacional do homem, ou seja, a Paideia. Diz ela: "o dever de cada um não consiste unicamente em se conformar com o modelo coletivo, mas antes em se individualizar, rivalizando em excelência." (Vergnières, 1998, p. 16)

É neste modelo ético que está inserido Heráclito. A ação moral transcende os costumes, de modo que a ética aristocrática refere-se ao comportamento do homem. É evidente que não se menciona o comportamento de qualquer homem, mas o comportamento do nobre. Vergnières (1998, p. 17) assinala que: "Precisamente, só o nobre é digno de formação; os outros podem, no máximo, receber um ensino artificial que lhes dará excelência fictícia." O caráter aristocrático, neste sentido, além da dimensão da excelência individual também encontra sentido nas condições que propiciam a excelência moral. A educação da solidão, como veremos, não depende de condições materiais, mas parte exclusivamente da dimensão 
interna do homem, então, a distinção nobre e servo passa a ser inócua, embora o vulgo não tenha acesso à sua excelência por estar dormindo.

Jaeger (1994, p. 224), por sua vez, aponta o caráter aristocrático da ética de Heráclito ao dizer que:

Até Sócrates, nenhum pensador desperta uma tão profunda simpatia pessoal como Heráclito. A magnífica altivez, oriunda da sua estirpe nobre, com que se revela aparece à primeira vista como um orgulho aristocrático revelador da verdadeira importância do seu próprio espírito.

Jaeger aprofunda o significado da sentença: Ethos é o dáimon do

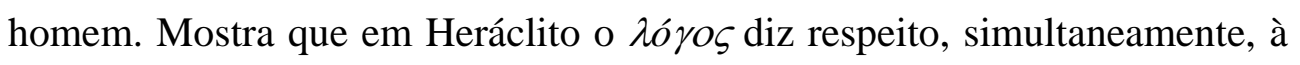
palavra e à ação. Nitidamente se apresenta uma relação do conhecimento com a vida. Em outros termos, muitas ações humanas e as palavras são

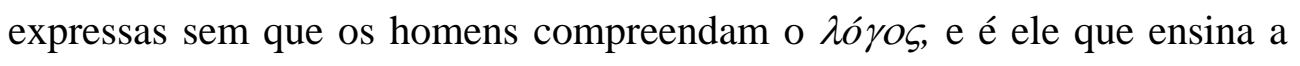

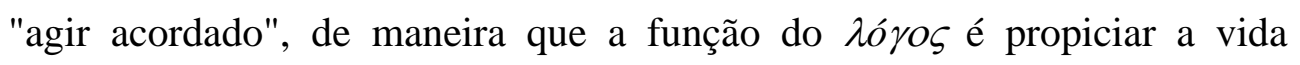
"desperta". A solidão é base da ética aristocrática no sentido de que a busca

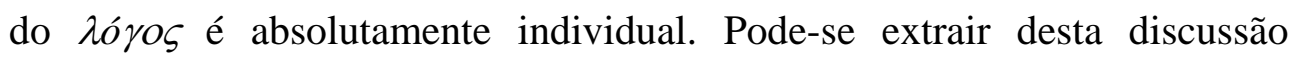
sugerida por Jaeger que a ética de Heráclito põe em relevo a busca pela superação do conhecimento, pois o homem não cônscio do $\lambda o ́ \gamma o \varsigma$ não atinge a sua plenitude e, portanto, não é capaz de revalorar os valores. Ainda sobre o efésio, diz Jaeger (1994, p. 225):

A natureza e a vida são um griphos, um enigma, um oráculo délfico, uma sentença sibilina. É preciso saber interpretar-lhes o sentido: Heráclito sente-se intérprete de enigmas, o Édipo da filosofia, que arranca os enigmas à Esfinge; é que a natureza gosta de se ocultar.

Heráclito é singular e sua ética é genuína na medida em que a busca da interpretação se faz por meio da crítica que se inicia na autocrítica que

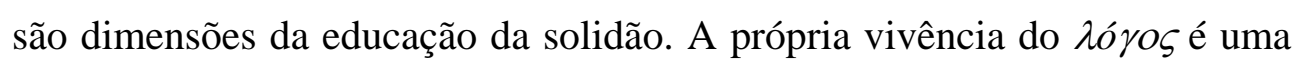
vivência por imagens, de tão profunda a sua dimensão e abrangência. A universalidade que o $\lambda o ́ \gamma o \varsigma$ propõe e a magnitude de envolvimento que abarca para o filósofo são pensadas em Heráclito a partir do exame dos

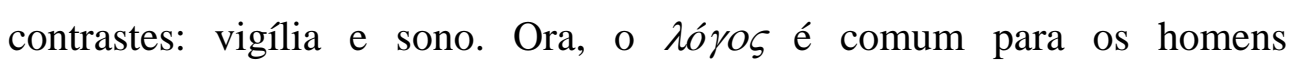


"despertos", unitário e o mesmo, enquanto que para os "adormecidos", este

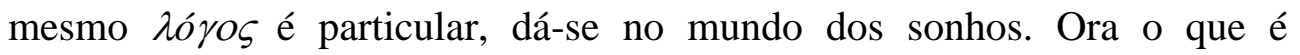
particular que não gera o universal? Isento do princípio de contradição aristotélico, pois o registro de Heráclito não contempla a lógica formal, temos o particular e universal como um e o mesmo. Então, sendo o ethos o

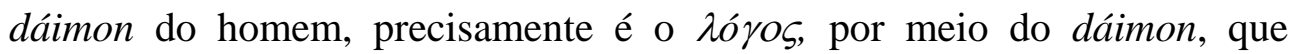
orienta a ação humana e isto se dá na solidão. É o $\lambda o ́ \gamma o \varsigma$ que justifica o critério ético da doutrina de Heráclito. É o ethos que fundamenta a educação da solidão, em última instância. Heráclito assevera que, segundo Kirk (1966, p. 216):

Os que falam com juízo devem apoiar-se no que a todos é comum, como uma cidade deve apoiar-se na lei, e com muito mais confiança. Pois todas as leis humanas são alimentadas por uma só, a lei divina; é que ela tem tanto poder quanto quer e para tudo ela é bastante e ainda sobra.

A dimensão do $\lambda o ́ \gamma o \varsigma$ na orientação do homem é de importância

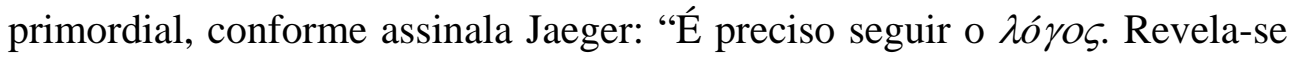
nele uma comunidade ainda mais alta e abrangente que a lei da pólis. É nele que a vida e o pensamento se devem basear. Cada qual pode 'tornar-se forte'

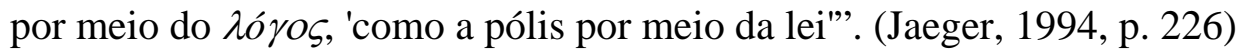

Desta maneira, Jaeger enfatiza o aspecto ético da doutrina de

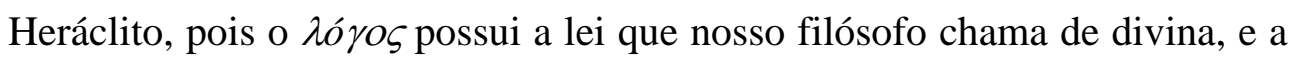
lei humana deve conter a divina. Mais do que isto, a doutrina de Heráclito surge como a primeira antropologia filosófica, contrapondo-se aos povos primitivos. É evidente que esta antropologia não se distancia das vertentes cosmológicas e teológicas, pois o homem de Heráclito é parte do cosmos. Por esta razão está submetido às leis do cosmos. Em última instância, a ética

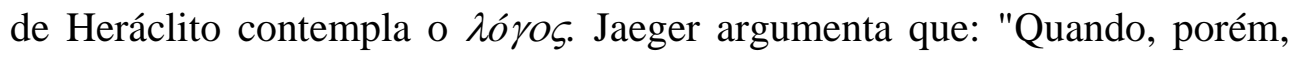
ganha consciência de que traz no seu próprio espírito a lei eterna da vida do todo, adquire a capacidade de participar da mais alta sabedoria, cujos decretos procedem da lei divina." (Jaeger, 1994, p. 228) 
Conclui Jaeger que o Ethos é o dáimon do homem fundamenta a ética heracliteana. Argumenta-se que esta ética alicerça a educação da solidão. A ética aristocrática subsidia a educação aristocrática, no sentido de que seu compromisso é com a individualidade, com a excelência do sujeito, com a possibilidade de superação do estado de ser. Tudo isto é possível a partir da própria consciência, isto é, de seu dáimon, ou seja, pela mais alta sabedoria de que o homem é capaz.

Guthrie (1962, p. 428) também enfatiza o aspecto da ordem universal do $\lambda o ́ \gamma o \varsigma$, ao afirmar:

Sendo universal e totalmente penetrante, este Logos - a lei pela qual o mundo é ordenado, e que pode ser compreendido pelas pessoas - é claro que é comum a tudo. Quando Herálito diz enfaticamente que nós temos que nos segurar rapidamente ao que é comum, ele quer dizer que é a força material e espiritual que traz a ordem racional. 1

Robin também assinala o aspecto da necessária harmonia entre a lei humana e a lei divina, argumentando que "Hay, en efecto, según Heráclito, una única ley divina, alimento de todas las leyes humanas." (Robin, s/d, p.102).

O caráter aristocrático e da ignorância do homem aparecem em diversos fragmentos. Assevera o efésio "Para quem profetiza Heráclito?: para os errantes noturnos, os magos, os bacantes, as mênades, os mistas. (...) É sem piedade que se iniciam nos mistérios em voga entre os homens." (Leão, 1991, p. 61) Ou seja, paradoxalmente, Heráclito profetiza para o vulgo, para o homem comum e distante do $\lambda o ́ \gamma o \varsigma$, afastado de seu papel no

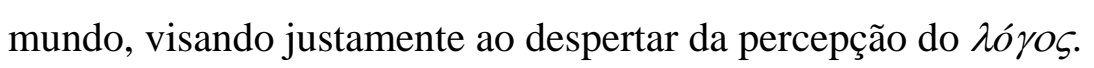

E também, diz ele: "O mais sábio dos homens, comparado com Deus, parecerá um macaco (tanto na ciência, como na beleza, como em tudo o mais). (...) Não é para se falar e agir dormindo". (Leão, 1991, p. 81)

\footnotetext{
${ }^{1}$ Tradução livre: "Being universal and all-pervading, this Logos - the law by which the world is ordered, and which can be comprehended in human minds - is of course common to all. When Heraclitus says emphatically that we must hold fast to what is common, he means this part-material, part-spiritual force which makes for rational order”.
} 
Com estes elementos da ética aristocrática em Heráclito passa-se a apresentar e a discutir aspectos da educação da solidão. A etimologia da palavra ética (ethos), tem como significado "morada", "costume", "comportamento", o que em Heráclito pode ser compreendido como vivência, ou seja, "a vivência do homem não tem conhecimento, mas a divina tem". Como foi possível observar ao longo destas reflexões, a ética aristocrática constitui-se de base para a educação aristocrática, compreendida neste artigo como educação da solidão.

\section{Educação da solidão}

Os pressupostos éticos da educação da solidão ancoram-se na dimensão aristocrática, isto é, na vertente de busca da excelência ou busca do melhor que se tem. Argumenta-se, a partir de Para Além de Bem e Mal” e "Humano, Demasiado Humano, de Friedrich Nietzsche, que a vida aristocrática é a marca da educação aristocrática. Nietzsche não escreveu sobre a educação aristocrática de forma sistemática, aliás, o filósofo da vontade de potência é o grande crítico dos estudos sistemáticos (Kaufmann, 1974). No entanto, suas considerações sobre a vida aristocrática, extraídas, respectivamente, dos últimos capítulos das obras mencionadas, conferem razões para a fundamentação da educação aristocrática (Mendonça, 2009), compreendida também como educação da solidão.

A educação da solidão é, radicalmente, educação da excelência, no sentido da busca da autocrítica e da autossuperação do sujeito. Este posicionamento se sustenta quando se pensa a vulgarização do ensino na atualidade, algo equivalente ao que ocorreu na Alemanha na época de Nietzsche, isto é, o sucateamento do ensino e a ênfase à dimensão profissional apontam para a necessidade de busca da excelência. Marton (2006, p. 18) assevera que:

No final do século XVIII, a cultura tinha de ser criação desinteressada, desligada de intenções utilitárias. Agora, ela está atrelada às exigências do momento, aos caprichos da moda, aos ditames da opinião pública. Antes, o ensino devia ser puro, 
desvinculado de objetivos práticos. Agora, com a proliferação dos institutos profissionais e escolas técnicas e com o esfacelamento das universidades em cursos especializados, ele converte-se em ensino de classe. Na Alemanha, a partir de 1870, desaparecem as inquietações com o cultivo do espírito humano e o desenvolvimento integral e autônomo do indivíduo. Educação e cultura acham-se submetidas ao reino da quantidade.

O ensino de classe é o ensino de rebanho, ensino para a massificação e aprisionamento. Por certo a educação da solidão pode significar alternativa à educação profissional, não como um modelo a ser implementado por políticas educacionais, mas, na dimensão individual, como concepção de educação que tem como pressuposto a conquista da excelência individual, isto é, a conquista da aristocracia.

A educação aristocrática volta-se para o desenvolvimento do homem solitário para a conquista de sua liberdade. “Um gênio não é nada se ele não nos leva para cima e não nos torna livres o bastante, para que então não mais tenhamos necessidade dele” (Nietzsche, 2007, p. 288). Eis a meta da educação aristocrática, educação dos indivíduos solitários. Ela deve conduzir o filósofo para o cume da montanha para que ele conquiste sua plenitude e liberdade. (Mendonça, 2009)

A educação da solidão em Nietzsche trata da educação da grande e nobre individualidade e, em última instância, refere-se à educação do indivíduo solitário: uma educação para os espíritos livres e que estejam dispostos a empreender a autocrítica para exercer a sua liberdade por meio da autossuperação. É neste sentido que se justifica a exposição da ética aristocrática em Heráclito; afinal, o efésio exerceu a vida aristocrática por excelência. Passa-se a analisar algumas passagens do último capítulo da obra de Nietzsche (1992) a fim de evidenciar os pressupostos éticos da educação da solidão.

No parágrafo 284, Nietzsche (1992, p. 191) introduz as quatro virtudes do homem nobre: “coragem, perspicácia, simpatia e solidão”. A solidão é tida como uma grande virtude do aristocrata, e marca a vida aristocrática na medida em que o homem nobre busca na solidão e no 
silêncio a compreensão das forças internas que tem: busca a sua excelência por meio da autocrítica e da autossuperação constantes. Estas características fundamentam a educação da solidão.

Nietzsche (1992, p. 192) define o que é aristocrático no parágrafo 287, mostrando que a "alma nobre tem reverência por si mesma". Continua dizendo que "toda filosofia também esconde uma filosofia, toda opinião é também um esconderijo, toda palavra é também uma máscara”

O filósofo finaliza o capítulo O que é nobre? e a obra Para Além de Bem e Mal com o parágrafo 296, tratando da profundidade e superficialidade de seus pensamentos, que se deixam escrever. É neste sentido que a dimensão da solidão é marca da vida do aristocrata. Passa-se a destacar, de forma também propedêutica, fundamentos do último capítulo de Nietzsche (2000).

A obra do período intermediário de Nietzsche (2000) dispõe, em seu último capítulo, O homem a sós consigo, de características da vida aristocrática. Esta vida tem como marca, como já se afirmou, a busca da crítica e da autocrítica pelo homem e, por esta razão, o parágrafo 483 inaugura esta parte do livro, assim: “convicções são inimigas da verdade mais perigosas que as mentiras” (Nietzsche, 2000, p. 265). Este parágrafo relaciona-se diretamente com a autocrítica e a autossuperação como bases da busca da excelência e, portanto, da educação aristocrática, por tratar da crítica ao dogmatismo por meio das convicções. Observa-se que os pressupostos éticos da educação sinalizam continuamente para a crítica de si mesmo, então, a educação da solidão não diz respeito à dimensão individualista, mas justamente o contrário, trata da grande e nobre virtude, isto é, da possibilidade de se alcançar a individualidade.

No parágrafo 511, Os fiéis às convicções, tem-se mais uma indicação dos perigos do dogmatismo, na perspectiva de que o dogmático não aceita sequer discutir as suas ideias. Assim, impossibilitado está para a busca da excelência, uma vez que não critica e muito menos se autocritica, não supera e muito menos se autossupera. “(...) aquele que trabalha a serviço de 
uma ideia nunca mais examina a ideia mesma, já não tem tempo para isso; e vai de encontro ao seu interesse considerá-la sequer discutível” (Nietzsche, 2000, p. 270). Os pressupostos éticos da educação da solidão sinalizam para a importância da própria filosofia, ou seja, a tentativa de superação do dogmatismo é tipicamente filosófica. Isto não significa dizer que os filósofos não sejam dogmáticos, aliás, o paradoxo da busca do conhecimento e de sua posse marca a vida de muitos filósofos.

Que sejamos fiéis à dureza e à rigidez da vivência individual e solitária, à honestidade intelectual e à busca da excelência, para possibilitar a vida aristocrática. A vida aristocrática coloca o homem frontalmente em contato consigo mesmo e sua compreensão cuidadosa e profunda faz com que ele veja muitas coisas ruins que tem internamente. Aliás, o que é o bom ou o ruim para Nietzsche? A vida individual e aristocrática evidencia para o homem aquilo que ele é, sem rodeios.

O homem nobre não se inferioriza pelo que é; ao contrário, assume o seu estado de ser com as qualidades e defeitos que tem. Assumir os defeitos é tarefa para o filósofo, para a alma nobre: “é prerrogativa da grandeza proporcionar enorme felicidade a pequeninos dons” (Nietzsche, 2000, p. 267). É igualmente importante assumir as virtudes que tem; logo, a busca da excelência refere-se a este contínuo movimento de busca de si mesmo, sem distinção do que se busca.

A solidão imputa-lhe esta tarefa de autopercepção e autocrítica, utilizando, para isto, a sua força interna. O interlocutor do aristocrata, nesse sentido, é ele mesmo. A vida solitária e individual é incomum como prática social e pouco defendida na sociedade, não acompanhando os discursos e perspectivas majoritários, seja no campo das ciências sociais, da política ou do direito. No entanto, sublinhamos que na perspectiva da moral aristocrática trata-se de uma vida mais importante que aquela tida como coletiva e social. Neste caso, parece possível explicar que a recusa e a crítica da vida individual coincidem, paradoxalmente, com a sua importância: tratase de uma vida genuína e singular, e que aponta para a consciência do 
homem no mundo por ele mesmo, diferente daquela reivindicada pela política moderna, em que a massificação social é o leitmotiv e, portanto, a singularidade se dilui.

Na ausência da singularidade e no enfraquecimento do sujeito, a sociedade passa a ser, como é a atual, massificada, produtora de mentes insanas, caóticas e não pensantes. Daí a importância da busca da excelência caracterizada pela busca da solidão como marca do homem do futuro, muito livre. Argumenta o filósofo do eterno retorno (Nietzsche, 2000, p. 297) que:

Existem pessoas tão habituadas a estar só consigo mesmas, que não se comparam absolutamente com outras, mas, com disposição alegre e serena, em boas conversas consigo e até mesmo sorrisos, continuam tecendo sua vida-monólogo. (...) Portanto, devemos conceder a certos indivíduos a sua solidão e não ser tolos a ponto de lastimá-los, como frequentemente sucede.

A vida solitária é, nesse sentido, uma opção clara de quem a adota, e não significa um problema para quem a deseja. Ao contrário, refere-se a uma vida singular e autêntica, própria e profunda. Por outro lado, há aqueles que optam por “insignificantes vivências diárias”, capazes de criar “o nada a partir do mundo” (p. 298).

Não buscar a excelência por meio do voltar-se para si mesmo é, no mínimo, viver a vida do outro. É evidente que o homem determinado a viver a vida do outro acredita ser autêntico. Acredita também viver a mais plena verdade possível, da mesma forma que os "inumeráveis que se sacrificaram por suas convicções acreditavam fazê-lo pela verdade absoluta” (Nietzsche, 2000, p. 300).

Para se pensar a educação da solidão é preciso revalorar a educação, isto é, ressignificar a educação a partir de outras bases. A revaloração ou, em outros termos, a superação da convicção, faz-se por quem tem a ousadia de inquirir a si mesmo, "superando a pretensão de defender a verdade absoluta” (Nietzsche, 2000, p. 301). Esta primeira ação de recusa do estatuto absoluto da verdade evidencia a busca da excelência e a vida solitária como 
marcas do filósofo e, portanto, descreve um importante pressuposto ético da educação da solidão.

Assim, deve-se buscar a singularidade em si mesmo, não obedecendo a leis externas, uma vez que essas leis, muitas vezes, não traduzem o desejo, a vontade, pois referem-se a leis heterônomas. A educação da solidão, portanto, reivindica o despertar do sujeito como condição da vida individual e singular.

\section{Considerações finais}

Como foi possível observar aos longos destas reflexões, a fundamentação ética para a educação da solidão apresenta características diferenciadas, porém, o principal foco é a dimensão da excelência individual, no sentido da educação aristocrática.

A discussão da ética aristocrática em Heráclito permitiu a compreensão da busca do ponto mais sublime da consciência, dáimon, como

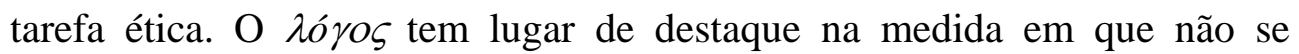

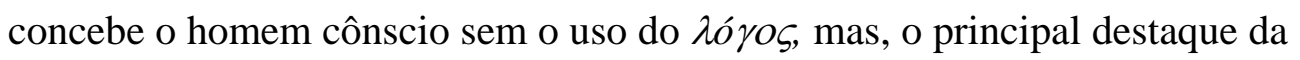
ética do efésio é por certo a sua vida, individual e solitária.

Nietzsche igualmente, embora em outro contexto, viveu a solidão e, portanto, sua experiência ao definir o homem como vontade potência e nada mais (Nietzsche, 2001) por certo forneceu mais fundamentos para a educação da solidão.

Por derradeiro, dentre os pressupostos éticos da educação da solidão tem-se a aristocracia, no sentido de excelência, então, em última instância, busca-se o que se tem de melhor em si mesmo. O que está em jogo na dimensão ética que fundamenta a educação da solidão é a conquista da excelência individual, algo que está à disposição de todos os homens que buscam a autocrítica e a autossuperação. 
Então, pode-se concluir que a resposta à pergunta do artigo sinaliza para três dimensões diferentes e complementares, quais sejam, (i) a busca de si mesmo, (ii) a crítica ao dogmatismo e (iii) vida individual e solitária.

É preciso esclarecer, por derradeiro, que a oportunidade de interlocução deste texto por ocasião do I Simpósio Nacional sobre Política, Ética e Educação, Poiethos, na Universidade Estadual de Campinas, e sua publicação neste Dossiê, representam o esforço do grupo Paideia, da Universidade Estadual de Campinas, no fortalecimento das discussões em torno dos fundamentos da educação no Brasil.

\section{Referências}

BAKER, S.Ernest. Teoria Politica Grega. Brasília: UnB, 1995.

GUTHRIE, W.K.C. The earlier presocratics and phthagoreans. London: Cambridge Un. Press, 1962.

JAEGER, W. Paidéia: a formação do homem grego. São Paulo: Martins Fontes, 1995.

KAUFMANN, Walter. Nietasche - Philosopher, Psychologist, Antichrist. 4.ed. New Jersey: Princeton Universtity Press, 1974.

KIRK e RAVEN, G.S e J.E. Os filósofos pré-socráticos. Trad. Carlos Alberto L.F., Beatriz Rodrigues B. e Maria Adelaide Pegado. Lisboa: Fundação C. Gulbenkian, 1966.

LEÃO, Emanuel C. Os pensadores originários. Rio de Janeiro: Vozes, 1991.

MARTON, Scarlett. Nieţssche: a transvaloração dos valores. 2.ed. São Paulo: Moderna, 2006.

MENDONÇA, Samuel. Ética Aristocrática em Heráclito. Revista Brasileira de Filosofia. São Paulo, v. LII, n. 211, 2003.

. Educação artistocrática em Nietzsche : perspectivismo e autossuperação do sujeito. 2009. 162p. Tese (Doutorado em Educação) - Faculdade de Educação, Universidade Estadual de Campinas, Campinas.

NIETZSCHE, Friedrich. Além do bem e do mal (sic). Prelúdio a uma filosofia do futuro. Trad. Paulo César de Souza. São Paulo: Cia das Letras, 1992. 
. Humano, demasiado bumano. Um livro para espíritos livres. Trad. Paulo César de Souza. São Paulo: Cia das Letras, 2000.

Letras, 2001.

A gaia ciência. Trad. Paulo César de Souza. São Paulo: Cia das - Escritos sobre Politica. Trad. Noéli Correia de Melo Sobrinho. São Paulo: Loyola, 2007, vol. I e II.

ROBIN, León. El Pensamiento Griego. Trad. Joaquín Xiráu Palau. Barcelona: Ed. Cervantes, s/d.

VERGNIÈRES, Solange. Ética e Política em Aristóteles. Trad. Constança Marcondes Cesar. São Paulo: Paulus, 1998. 